\title{
The incidence of immunofluorescence patterns and specific autoantibodies observed in autoimmune patients in a tertiary care centre
}

\author{
${ }^{1}$ Molecular Genetics Laboratory, Medanta - The Medicity, Gurgaon, India \\ ${ }^{2}$ Amity Institute of Biotechnology, Amity University, Noida, India
}

\section{KEY WORDS}

anti (ANA); autoimmune diseases (ADs); indirect immunofluorescence (IIF); extractable nuclear antigens (ENA); autoantibodies

\section{Corresponding author}

Shoma Paul Nandi

Centre Head for Cellular

and Molecular Biotechnology

Amity Institute of Biotechnology

Amity University Uttar Pradesh

Sector 125, Noida 201313, India

E-mail: spaul@amity.edu

Phone: +919810324673

Fax: +91 1204392947

Doi

10.23822/EurAnnACI.1764-1489.93

\begin{abstract}
Summary
Objectives. Testing for antinuclear antibodies (ANA) facilitates the diagnosis of autoimmune diseases $(A D s)$. Here, we report an incidence of ANA positivity and its patterns by indirect immunofluorescence (IIF) and specific autoantibodies through immunodot assay. Methods. Sera from 993 patients presenting with various ADs were tested by IIF and immunodot assay. Results. ANAs were detected in 39.7\%, of which speckled pattern was predominantly observed (50.8\%). 56.8\% of samples were positive on the immunodot assay, with SSA Ro 60 antibody being the most prevalent $(30.7 \%)$. Discussion. A significant correlation $(p<0.0001)$ was observed between patterns and auto-antibodies. Coarse speckled (CS) and homogeneous were overly represented by antibodies SSA Ro 60 (13\%) and nucleosomes (5.8\%), respectively. Mi-2, PL-7, PL-12, and SP-100 were the rarest autoantibodies specificities found. Conclusions. The presence of a particular IIF pattern is predictive of a specific autoantibody in the sample. Association of IIF patterns and specific autoantibody are relevant for a more accurate diagnosis of disease.
\end{abstract}

\section{Introduction}

Autoimmune diseases (ADs) arise due to the pathologic activity of the immune system of an organism, directed against its own cells and tissues leading to the production of autoantibodies (1). However, the etiology of these conditions is unclear. Studies have suggested a controversial functional role of environmental factors, drugs, chemicals and toxins in triggering $\mathrm{ADs}$ (2).

The geo-epidemiology of ADs has grabbed attention recently (3-5). Studies have identified considerable variability in the epidemiology of different $\mathrm{ADs}$, ranging from common, such as Hashimoto's thyroiditis and rheumatoid arthritis with a reported prevalence of approximately $1 \%$, to others that are so rare that the only clues to their prevalence are a small number of case reports and small studies (6-10). Overall, the prevalence of a broad group of ADs is $12.5 \%$ (11). Studies in some centers in India reported the prevalence of presence of common
ADs from 7.5 to $12 \%$, which indicated a significant health care burden (12).

Serum antibodies against nucleus and anti-extractable nuclear antigens (ENA) are widely used in clinical practice and are included in the diagnosis of ADs $(13,14)$. The most common autoantibodies are ANAs, which are conventionally assessed by IIF and include antibodies to both nuclear and cytoplasmic components (15). The immunofluorescence staining patterns and specific autoantibodies are clinically relevant as they are associated with particular ADs (16). Due to the ethnic variations, genetic and environmental factors, there is a significant variation in incidence and disease-specific autoantibodies $(17,18)$. Nonetheless, ANA is frequently found in a considerable proportion of healthy subjects although studies are generally performed in selected populations, such as blood donors or employees, while data on ANA prevalence (19-21) and clinical significance over time (22) in an unselected general population, are limited. 
In light of the above backdrop, this study hypothesized that a definite spectrum of autoimmune disorders might correlate with the clinicopathological endpoints of the disease, and therefore investigated the epidemiological profile of ANA staining patterns by IIF and specific autoantibodies through immunodot assay from patients presenting with autoimmune disorders in a tertiary care hospital. Taken together, the results of this study may throw intriguing insights on the detection of specific autoantibodies with a specific ANA staining pattern.

\section{Materials and methods}

\section{Study population and specimens}

A total of 993 consecutive patients clinically suspected of various autoimmune disorders were recruited with written informed consent from January 2016 to October 2016, from different medical specialties of the hospital. The study protocol conformed to the provisions of the 1975 Declaration of Helsinki (as revised in Seoul, Korea, October 2008).

Whole blood was collected from the patients by venipuncture into plain vacutainers, and separated sera were stored at -80 ${ }^{\circ} \mathrm{C}$ until assessed. However, to prevent repeated freezing and thawing, serum aliquots were immediately processed to prevent discrepancies in results. Based on standardized assays used in our laboratory, screening of ANA was achieved through indirect immunofluorescence assay using Hep- 2 substrate, and specific autoantibodies were confirmed by immunodot assay using a panel of 25 nuclear and cytoplasmic antigens.

\section{Indirect immunofluorescence (IIF)}

Screening of ANAs was performed using the Bio-Rad Kallestad Hep-2 substrate (cat no. 30472). Screening dilution of 1:80 was used for adult patients and 1:40 was used for pediatric patients. Briefly, samples were processed using an automated processor (Bio-RAD, serial no. 2003-215). Positive samples were further diluted till 1:320 to determine the titer. Serum diluted in phosphate buffered saline (PBS) was incubated with fixed Hep-2 cell substrate for 30 minutes at room temperature. Slides were washed twice for five minutes with PBS, incubated for an additional 30 minutes with fluorescent-labeled conjugated anti-human IgG (cat no. 30446). Subsequently, a cover-slip was placed over the slide and analyzed using a fluorescence microscope at 40x magnification. The fluorescence of each sample was compared with the negative control, and the pattern of fluorescence was determined and recorded.

\section{Immunodot assay}

Immunodot assay is based on classical enzyme immuno assay (EIA) in which multiple parameters can be tested simultane- ously. D-tek Blue Diver ANA Quantrix (cat no. ANA25Q-24) system was used for the quantitative detection of a 25-antigen panel according to manufacturer's instructions. Purified nucleosomes, ds-DNA, histones, Sm, RNP68kD/A/C, Sm/RNP, SSA/Ro 60kD, SSA/Ro 52kD, SSB, Scl-70, Ku, PM-Scl 100, Mi-2, Jo-1, PL-7, PL-12, SRP-54, Ribosomes P0, CENP-A/B, PCNA, sp100, gp210, M2 recombinant, M2 native and F-actin are bound in triplicate on the nitrocellulose membrane. Two sample controls, a calibration curve with blank measurement, conjugate controls, and substrate controls are also present in triplicate in the strip (figure 1). Post assay, strips were scanned and the intensities were evaluated using a computerized Dr. Dot software. Specifically, samples with values $>6 \mathrm{AU} / \mathrm{ml}$ were considered positive, samples $<6 \mathrm{AU} / \mathrm{ml}$ negative.

\section{Statistical analysis}

Categorical variables were expressed as a percentage, and a twotailed probability level of $\mathrm{p}<0.05$ was considered statistically

Figure 1 - Immunodot assay strips (D-Tek) showing control and positive sample strip.

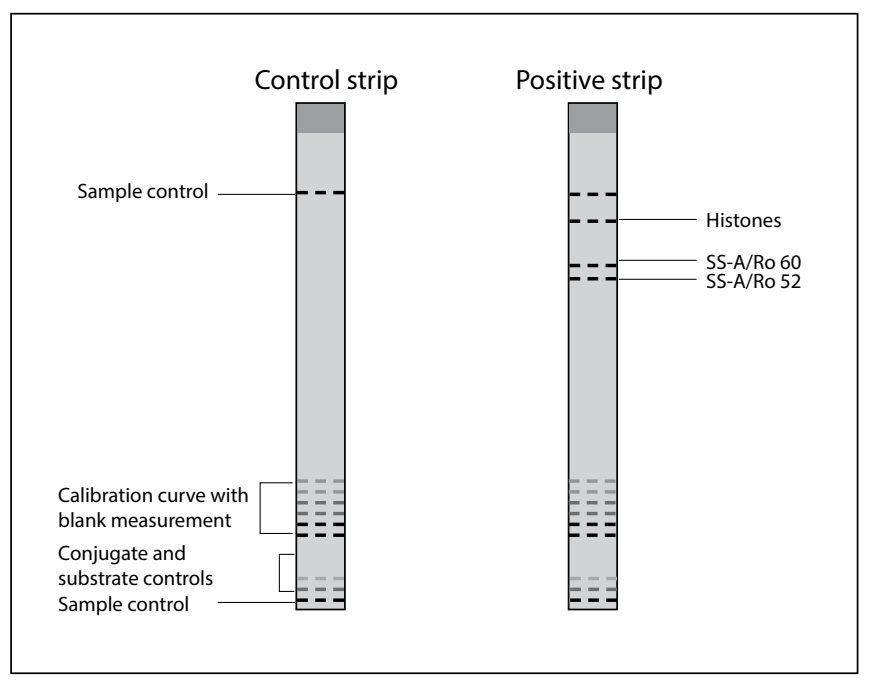

Nuc, nucleosomes; dsDNA, double stranded DNA; His, histones; Sm, Smith; RNP68kD, ribonucleoprotein 68; Sm/RNP, Smith antigen/ribonucleoprotein; SS-A /Ro60 kD, soluble substance A/ Robert antigen $60 \mathrm{kDa}$; SS-A/Ro $52 \mathrm{kD}$, soluble substance A/Robert antigen $52 \mathrm{kDa}$; SS-B, soluble substance B; Scl-70, scleroderma antigen $70 \mathrm{kDa}$; Ku, DNA helicase; PM-Scl 100, polymyositis scleroderma $100 \mathrm{kDa}$; Mi-2, chromodomain helicase DNA binding protein4; Jo-1, histidyl-tRNA synthetase/John-P; PL-7, threonyl-tRNA synthetase; PL12, alanyl t-RNA synthetase; SRP54, signal recognition particle 54; CENP$\mathrm{A} / \mathrm{B}$, centromere protein A/B; PCNA, proliferating cell nuclear antigen; sp100, sp100 nuclear antigen; gp210, nuclear pore glycoprotein-210; M2 rec, mitochondrial recombinant protein; M2 native, mitochondrial native protein; F-actin, filamentous actin. 
significant. All computations were performed considering $80 \%$ power and $95 \%$ confidence interval using IBM SPSS, Ver20 (http://www-01.ibm.com/software/analytics/spss/) statistical software. Association of patterns with the antibodies were analyzed using a chi-square test.

\section{Results}

\section{The incidence of serum ANA and specific autoantibodies}

Upon IIF investigation, serum ANA was detected in 55.9\% (555 out of 993) at 1:80 dilution, of which $70.9 \%$ (394/555) were positive at titers $\geq 1: 160$. Among the various patterns observed in ANA-positive cases, the most common pattern was homogeneous $26.4 \%(104 / 394)$, then fine speckled $25.9 \%$ $(102 / 394)$ and coarse speckled $24.9 \%$ (98/394). $11.4 \%$ (45/394) serum samples had more than one immunofluorescence pattern. 56.8\% (224/394) samples were positive by immunodot assay. Among these, SSA Ro 60 (30.7\%) was found to be the most prevalent antibody along with SSA Ro 52 in $26.1 \%$ cases. Mi-2, PL-7, PL-12, and SP-100 were the rarest autoantibodies specificities found (table I).

\section{Correlation of ANA patterns with specific autoantibodies}

The presence of a specific autoantibody is associated with a specific immunofluorescence pattern. A significant association $(\mathrm{p}<0.0001)$ was observed between patterns and an-

Table I - Distribution of various ANA patterns and antibodies against specific antigens in "ANA positive (> = 1:160)" patients $(n=394)$.

\begin{tabular}{cccc}
\hline Immunofluorescence & \multicolumn{3}{c}{ Immunodot assay } \\
\hline pattern & number of positive samples (\%) & antigen & number of positive samples (\%) \\
\hline HOM & $104(26.4)$ & SSA Ro60 & $121(30.7)$ \\
\hline FS & $102(25.9)$ & SSA Ro52 & $103(26.1)$ \\
\hline CS & $98(24.9)$ & SSB & $48(12.2)$ \\
\hline NUC & $28(7.1)$ & Sm/RNP & $40(10.2)$ \\
\hline CENT & $17(4.3)$ & nucleosomes & $39(9.9)$ \\
\hline HOM with NUC & $17(4.3)$ & RNP68 & $28(7.1)$ \\
\hline FS with NUC & $11(2.8)$ & dsDNA & $28(7.1)$ \\
\hline MP & $7(1.8)$ & histones & $26(6.6)$ \\
\hline FS with MND & $5(1.3)$ & Sm & $24(6.1)$ \\
\hline MND & $3(0.8)$ & Scl-70 & $24(6.1)$ \\
\hline CS with FND & $2(0.5)$ & CENP-A/B & $21(5.3)$ \\
\hline & PCNA & $13(3.3)$ \\
\hline & SRP-54 & $4(1.0)$ \\
\hline & M2-recombinant & $3(0.8)$ \\
\hline & M2-native & $3(0.8)$ \\
\hline & F-actin & $3(0.8)$ \\
\hline & PM-Scl-100 & $2(0.5)$ \\
\hline & Ku & $2(0.5)$ \\
\hline & Rib-P0 & $2(0.5)$ \\
\hline & Mi-2 & $1(0.3)$ \\
\hline & PL-7 & $1(0.3)$ \\
\hline & PL-12 & $1(0.3)$ \\
\hline & SP-100 & $1(0.3)$ \\
\hline
\end{tabular}

HOM, homogeneous; FS, fine speckled; CS, coarse speckled; NUC, nucleolar; CENT, centromere; HOM with NUC, homogeneous with nucleolar; FS with NUC, fine speckled with nucleolar; MP; mixed pattern; FS with MND, fine speckled with multiple nuclear dots; MND, multiple nuclear dots; CS with FND, coarse speckled with few nuclear dots. 
tibodies. Coarse speckled and homogeneous were overly represented by antibodies SSA/Ro $60(13 \%)$ and nucleosomes $(5.8 \%)$, respectively. Homogeneous with the nucleolar pattern was detected only by the Scl-70 antibody, while other patterns like coarse speckled were detected by fourteen different antibodies (table II). Fluorescent images of common and rare patterns are shown in figure $\mathbf{2}$ and figure 3.

Incidentally, while studying the correlation of IIF patterns and specific autoantibodies, we found the autoantibody distribution in different ADs (figure 4, figure 5). In hypothyroidism, coarse speckled is the common pattern along with SS-A Ro52 being the most common antibody found. Out of 41 SLE samples, homogeneous (15/41) is the most common pattern and SSA Ro 60, SSA Ro 52, nucleosomes, SS-B and dsDNA antibodies are the predominant antibodies. Homogeneous with nucleolar pattern was found to be associated with Scl-70 in scleroderma. A coarse speckled pattern with SSA Ro 60 was predominant in Sjögren's syndrome.
Figure 2 - Common ANA patterns by IIF: a, negative sample; $b$, homogeneous; $c$, fine speckled; $d$, coarse speckled; $e$, nucleolar; $f$, centromere.
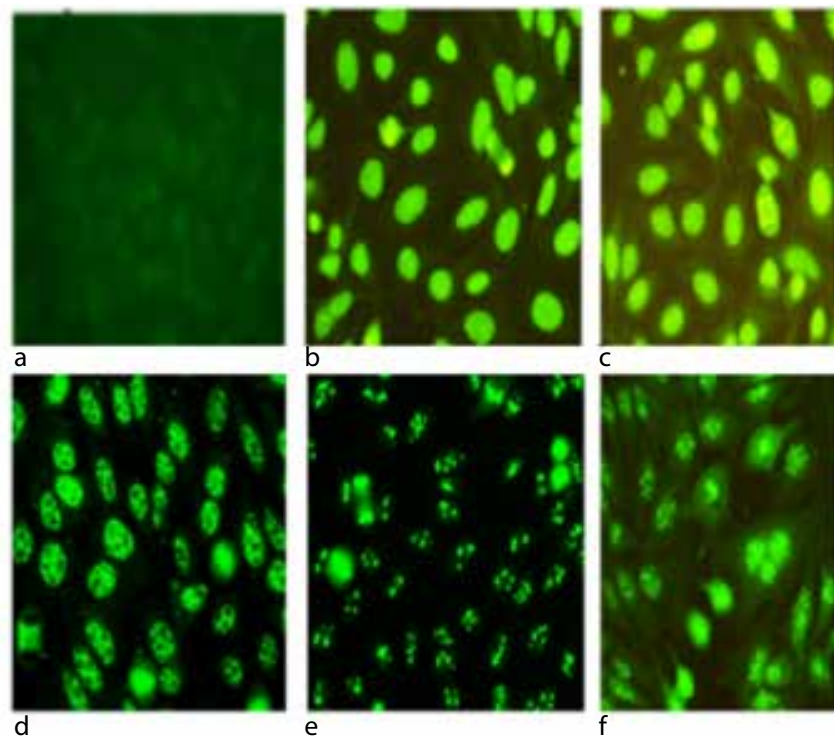

Table II - Correlation of IIF patterns and specific autoantibodies (data is expressed in percentage).

\begin{tabular}{|c|c|c|c|c|c|c|c|c|c|}
\hline Autoantibody & FS & NUC & CS & CENT & HOM & MP & MND & HOM with NUC & FS with NUC \\
\hline nucleosome & 0 & 0.7 & 1.4 & 0.3 & 5.8 & 1.0 & 0 & 0 & 0 \\
\hline Scl-70 & 0 & 0.3 & 0 & 0 & 1.4 & 0 & 0 & 2.7 & 0 \\
\hline Mi-2 & 0 & 0 & 0 & 0 & 0.3 & 0 & 0 & 0 & 0 \\
\hline SRP-54 & 0 & 0 & 0 & 0 & 0.7 & 0 & 0 & 0 & 0 \\
\hline CENPA/B & 0.7 & 0 & 0.3 & 1.4 & 0 & 0 & 0 & 0 & 0 \\
\hline dsDNA & 0 & 0.3 & 1.0 & 0 & 4.8 & 0 & 0 & 0 & 0 \\
\hline PCNA & 1.4 & 0.3 & 0.3 & 0.3 & 1.4 & 0.3 & 0 & 0 & 0 \\
\hline sp100 & 0 & 0 & 0 & 0 & 0 & 0 & 0.7 & 0 & 0 \\
\hline Sm & 0 & 0 & 1.4 & 0 & 1.4 & 1.0 & 0 & 0 & 0 \\
\hline RNP68kD/A/C & 0 & 0 & 2.1 & 0 & 1.0 & 0.7 & 0 & 0 & 0 \\
\hline Sm/RNP & 0 & 0 & 3.1 & 0 & 1.7 & 1.0 & 0 & 0 & 0 \\
\hline SSA Ro 60kD & 3.1 & 0 & 13.0 & 0 & 5.5 & 1.0 & 0 & 0 & 0 \\
\hline SSA Ro 52kD & 1.4 & 0 & 10.3 & 0.3 & 4.8 & 0.7 & 0 & 0 & 0.3 \\
\hline SSB & 1.0 & 0 & 4.4 & 0 & 3.0 & 1 & 0 & 0 & 0 \\
\hline
\end{tabular}

FS, fine speckled; HOM, homogeneous; CS, coarse speckled; CENT, centromere; HOM, homogeneous; MP, mixed pattern; HOM with NUC, homogeneous with nucleolar; FS with NUC, fine speckled with nucleolar. 
Figure 3 - Rare ANA patterns by IIF: a, PCNA (proliferating cell nuclear antigen); $b$, NUMA (nuclear mitotic apparatus); $c$, homogeneous with nucleolar; $d$, nuclear dots; e, Jo-1 pattern; $f$, mid body pattern.
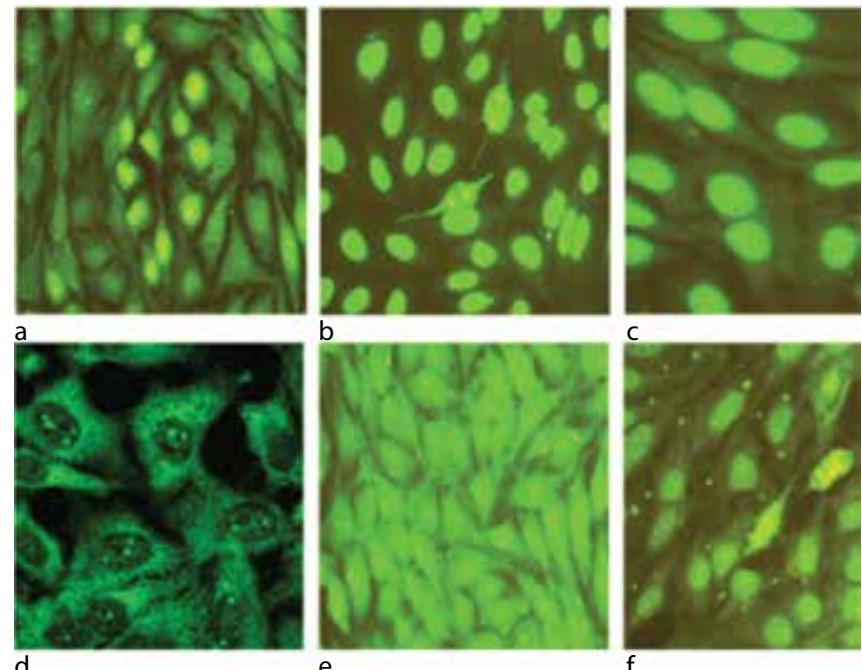

\section{Comparison of results of IIF and immunodot assay}

Out of 993 samples, 55.9\% (555) were ANA-IIF positive at 1:80 serum dilution. Of these positive ANA-IIF, $45.9 \%$ (255) were also immunoassay positive. ANA pattern observed in $555(55.9 \%)$ cases were mostly fine speckled 203 (36.6\%); homogeneous 131 (23.6\%); coarse speckled 112 (20.2\%); nucleolar 38 (6.8\%); fine speckled with nucleolar $18(3.2 \%)$, homogenous with nucleolar $17(3.1 \%)$. Eight $(1.4 \%)$ cases exhibited a mixed pattern, and $5(0.9 \%)$ cases showed fine specked with multiple nuclear dot pattern. (figure 6)

Out of 324 IIF negative samples, 48 (14.8\%) were positive with the immunodot assay. Twelve sera showed significant value for SSA/Ro-60 (25\%) with a mean intensity of 47 on dot assay; 15 sera showed positivity for nucleosomes (31\%), although the mean intensity of 10 is not significant (table III). Clinical features of these IIF negative samples were hypothyroidism (2/48), myositis (4), arthritis (3/48), SLE (2/48), spondyloarthritis $(1 / 48)$, CTD $(1 / 48)$, diabetes mellitus (1/48), SLE + vasculitis (1/48), RA + vasculitis (1/48), $\mathrm{RA}+$ diabetes mellitus (1/48), RA + hypothyroidism (1/48).

Figure 4 - Distribution of IIF patterns in ANA-positive patients $(n=394)$.

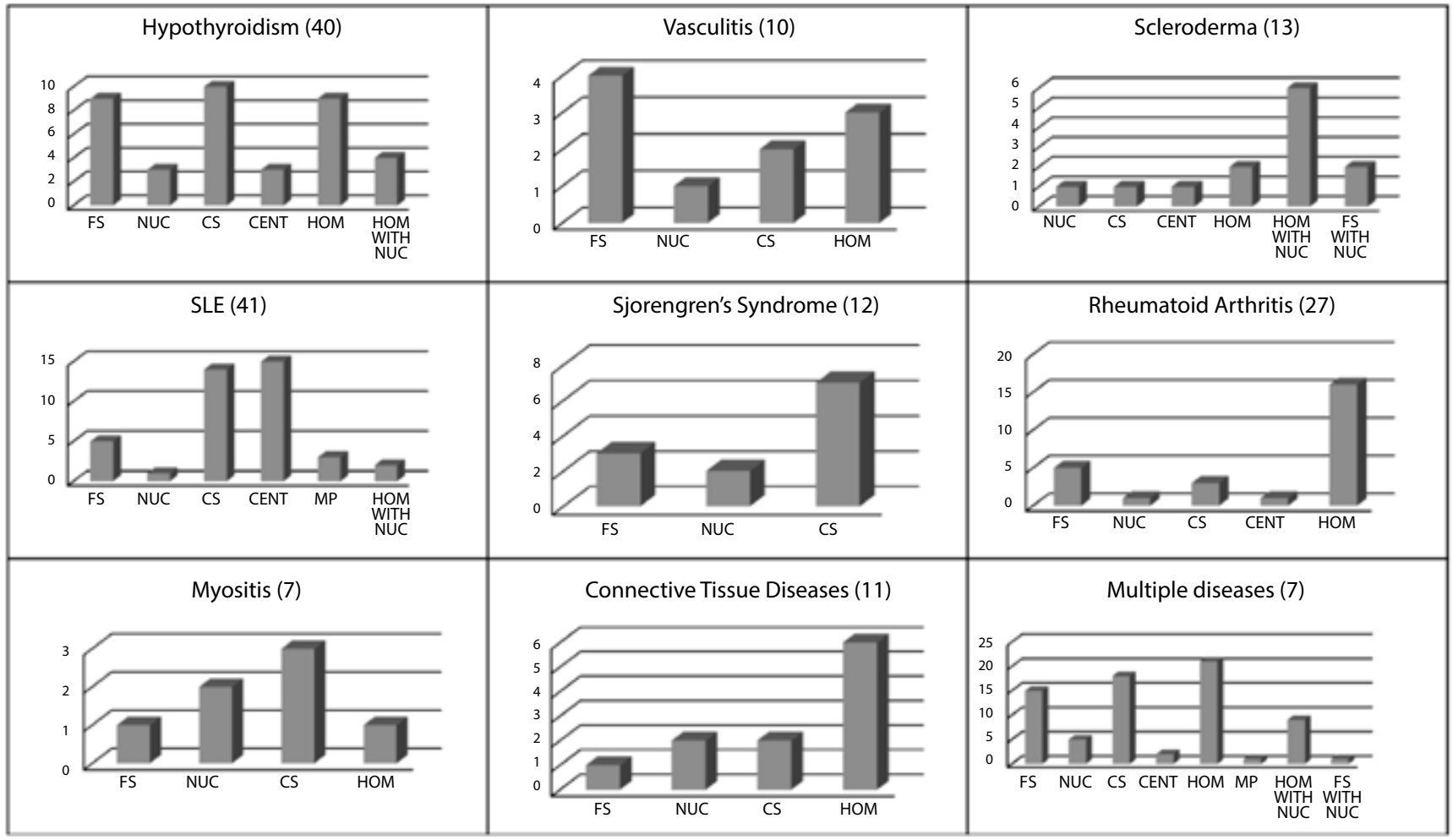


Figure 5 - Distribution of autoantibodies in ANA-positive patients ( $n=394)$.

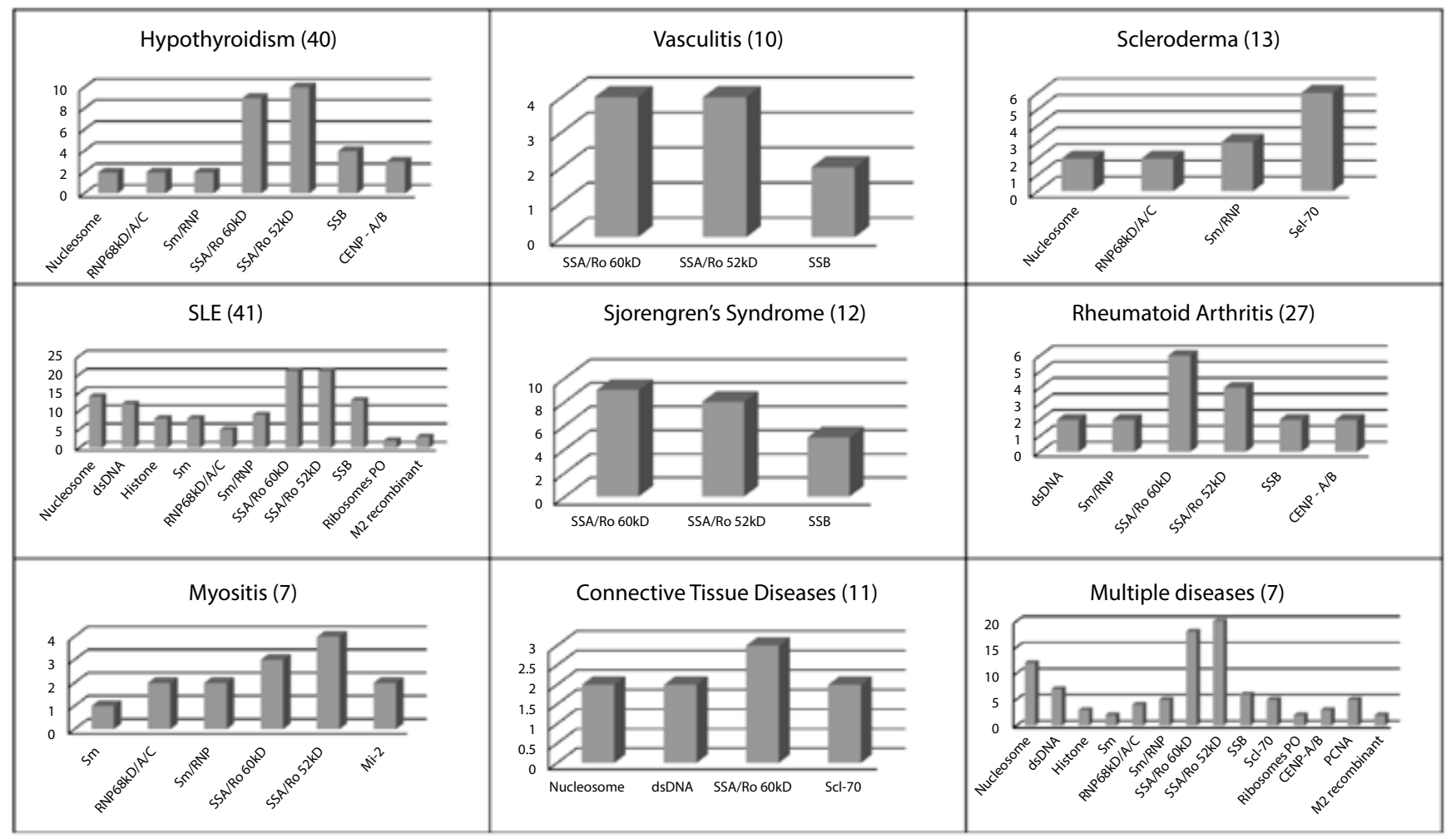

Figure 6 - Summary of immunoassays $(n=993)$

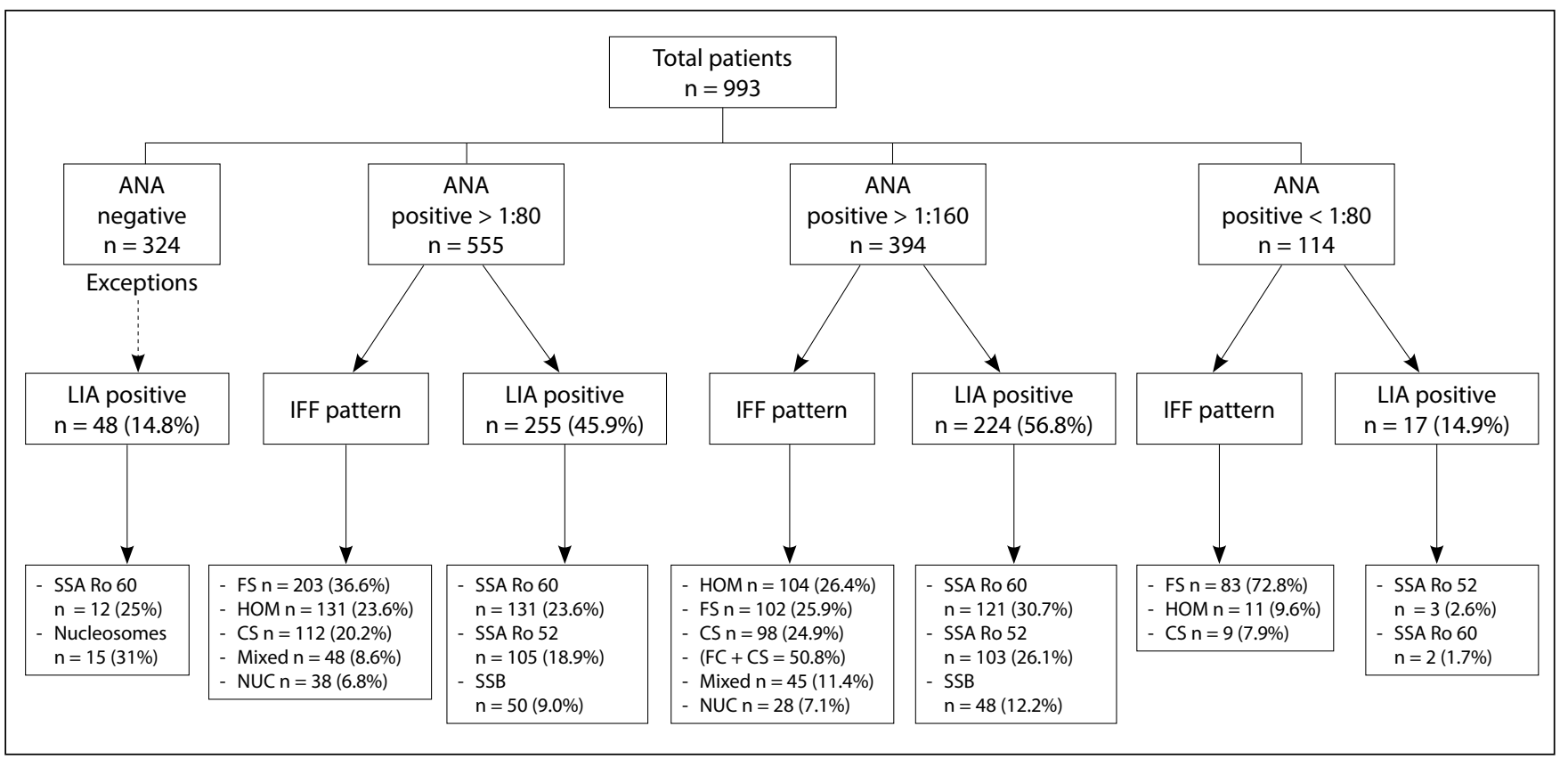


Table III - Autoantibody intensity in immunodot positive samples and IIF negative samples $(n=48)$.

\begin{tabular}{ccc}
\hline Autoantibody & $\begin{array}{c}\text { Number } \\
\text { of positive } \\
\text { samples by } \\
\text { immunodot } \\
\text { assay }\end{array}$ & $\begin{array}{c}\text { Results in mean } \\
\text { intensity (AU/ml) }\end{array}$ \\
\hline nucleosomes & 15 & 10 \\
\hline dsDNA & 3 & 9 \\
\hline histones & 2 & 10 \\
\hline Sm & 1 & 11 \\
\hline RNP 68 KD/A/c & 1 & 11 \\
\hline SSA Ro 60 & 12 & 47 \\
\hline SS A Ro 52 & 5 & 51 \\
\hline SS-B & 2 & 26 \\
\hline PM-Scl & 1 & 10 \\
\hline Jo-1 & 3 & 94 \\
\hline SRP-54 & 8 & 12 \\
\hline centromere & 2 & 14 \\
\hline M2 recombinant & 2 & 44 \\
\hline F-actin & 3 & 14 \\
\hline
\end{tabular}

\section{Discussion}

Serum ANA are important biomarkers in the diagnosis of ADs. IIF is considered as a gold standard screening assay due to its high sensitivity. In the present study, we focused on the incidence of IIF patterns and specific autoantibodies in patients clinically suspected of ADs. IIF was compared with immunodot assay to predict the specific antibodies associated with a specific pattern. The most common IIF patterns observed were speckled $(50.8 \%)$ [fine speckled $(25.9 \%)+$ coarse speckled $(24.9 \%)$ ], homogeneous $(26.4 \%)$, nucleolar $(7.1 \%)$, centromere $(4.3 \%)$, which were similar to study conducted in Bangladeshi population where speckled pattern $(50.8 \%)$, peripheral pattern (21.64\%), homogenous (18.1\%) and nucleolar pattern (9\%) were observed (23). Another study reported speckled (42.5\%) as the most common fluorescence pattern, followed by homogeneous (41.4\%) and nucleolar (10.6\%) (24). Our results are different when compared to study by Kun-Yi Wang et al. which reported common patterns as homogeneous $(42 \%)$, mixed $(23.9 \%)$, speckled $(16.9 \%)$, centromere $(9.3 \%)$, and nucleolar $(7.9 \%)$ except nucleolar prevalence which was similar to our study (25-26). These differences may be due to the ethnic variations and biological heterogeneity of serological immune response (17). Of the 45 patients with rare and mixed patterns (figure 3), 16 were diagnosed with an autoimmune disease: six patients with scleroderma, six patients with SLE, one with rheumatoid arthritis, one patient with Sjögren's syndrome, two patients with SLE and scleroderma overlap, indicating the importance of rare patterns. However, Pieter Vermeersch et al. concluded that the observation of a rare ANA pattern could be helpful for the diagnosis of specific ADs, but the clinical significance is low when found as part of a routine clinical investigation (27), and may be considered as not important. It is important to remember that there are some non-autoimmune causes of rare ANA patterns on IIF, which include carcinoma, hepatitis $\mathrm{C}$ infection, and transplantation (28-30). In the present study, out of 15 cases of malignancies, 2 cases were positive for common antibody SSA-Ro60, and rare antibody SRP-54 (1), CENP-A/B (1), sp-100(1) and F-actin (3) were found.

Anti-SSA Ro60 (30.7\%), is the most common autoantibody including anti-SSA Ro52 (26.1\%) and anti-SSB (12.2\%), which is comparable to study in Korean patients where anti-Ro52 $(66.7 \%)$ was the most frequently detected antibody, followed by anti-Ro60 (52.1\%) and anti-La (49.0\%) (31). Study on US population also reported anti-Ro-52 as the common antibody which is similar to the findings of this study (32). Being the gold standard technique, ANA detection by IIF did not match with 48 samples which were positive by immunodot assay, and out of these, 18 samples were of autoimmune etiology (table III) and 30 samples were of multiple diseases. SS-A/Ro 60 (12/48), and SS-A/Ro $52(5 / 48)$ are significantly missed by IIF. This difference is also observed in the literature, that SSA R060 is missed by Hep-2 cells due to the low cellular abundance of this particular protein on Hep-2 cells (33). These differences may also be due to the subjectivity and the inter-operator variability of performing the assay. These technical differences have been observed earlier in literature, and this is one of the major limitations of using IIF as a screening assay for the detection of autoantibodies. Although the validation studies have been performed for automated IIF $(34,35)$, they are not routinely used in developing countries due to the expenses involved.

To understand the association of IIF patterns with specific autoantibodies, our finding was compared to standard reference as well as with earlier studies, and found to be very similar with published literature (table IV). The speckled pattern showed an association with SS-A/ Ro 60 and SS-A/Ro 52, which was similar to other studies. Likewise, the centromere pattern is shown in association with the CENP-B antibody, in accordance with other published studies. However, there are some exceptions, like histones in a coarse speckled pattern, Scl-70 in the homogeneous pattern, which may be due to the use of different detection techniques. This correlation is very helpful in predicting a specific antibody with a particular ANA pattern. 
Table IV - Comparison of association of IIF patterns with specific autoantibody in different studies.

\begin{tabular}{|c|c|c|c|c|}
\hline Patterns & $\begin{array}{l}\text { Common autoantibody } \\
\text { associations in present study }\end{array}$ & Western textbook $(36,37)$ & Indian study (38) & Standard reference (16) \\
\hline fine speckled & SSA Ro 60 kD, SSA Ro 52 kD & $\begin{array}{l}\text { Sm, RNP, Scl-70, SSA/Ro 52, } \\
\text { SSB, RNA pol I and II, and } \\
\text { other antigens }\end{array}$ & Sm, RNP, SSA/Ro 52, SSB & $\begin{array}{l}\text { SSA/Ro, SSB/La, Topo- } \\
1 \text {, common to many } \\
\text { antigens }\end{array}$ \\
\hline nucleolar & $\begin{array}{l}\text { SSA Ro } 60 \mathrm{kD} \text {, SSA Ro } 52 \mathrm{kD} \text {, } \\
\text { nucleosomes }\end{array}$ & Nucleolar RNA & Scl-70, SSA/Ro 52, SSB & $\begin{array}{l}\text { PM/Scl, RNA- } \\
\text { polymerase, URNP, } \\
\text { U3-RNP, To/Th }\end{array}$ \\
\hline $\begin{array}{l}\text { coarse } \\
\text { speckled }\end{array}$ & $\begin{array}{l}\text { SSA Ro 60, SSA Ro } 52 \text { kD, SS- } \\
\text { B, Sm/RNP, RNP } 68 \text { kD/A/C, } \\
\text { Sm, histones }\end{array}$ & $\begin{array}{l}\text { Sm, RNP, Scl-70, SSA/Ro 52, } \\
\text { SSB, RNA pol I and II and } \\
\text { other antigens }\end{array}$ & Sm, RNP, SSA/Ro 52, SSB & $\begin{array}{l}\text { U1-SnRNP, U2-6snRNP } \\
(\mathrm{Sm}) \text {, nuclear matrix }\end{array}$ \\
\hline centromere & CENP-A/B & centromere protein & centromere protein-B & $\begin{array}{l}\text { kinetochore, CENP-A, } \\
\text { B, C, F }\end{array}$ \\
\hline
\end{tabular}

\section{Conclusions}

In conclusion, ANAs detection is very crucial for the evaluation of patients suffering from various $\mathrm{ADs}$. This study provided the correlation of IIF patterns and specific autoantibodies, along with incidence in a tertiary care centre. The presence of a particular IIF pattern is predictive of a specific autoantibody in the sample. Association of IIF patterns and specific autoantibody are relevant for a more accurate diagnosis of disease. The immunodot assay is very helpful in the diagnosis of clinically suspected cases of an overlap syndrome. These findings should be kept in mind by physicians while assessing ANA results, and will be useful in deciding further investigation for the diagnosis of specific ADs.

\section{References}

1. Smith DA, Germolec DR. Introduction to immunology and autoimmunity. Environ Health Perspect 1999; 107Suppl 5:661-665.

2. Selmi C. The worldwide gradient of autoimmune conditions. Autoimmun Rev 2010; 9:A247-250.

3. Ljubojevic S, Lipozencic J. Autoimmune bullous diseases associations. Clin Dermatol 2012; 30:17-33.

4. Pons-Estel GJ, Ugarte-Gil MF, Alarcon GS. Epidemiology of systemic lupus erythematosus. Expert Rev Clin Immunol 2017; 13:799-814.

5. Simon TA, Kawabata H, Ray N, Baheti A, Suissa S, Esdaile JM. Prevalence of Co-existing Autoimmune Disease in Rheumatoid Arthritis: A Cross-Sectional Study. Adv Ther 2017; 34:2481-2490.

6. Lerner A, Jeremias P, Matthias T. The World Incidence and Prevalence of Autoimmune Diseases is Increasing. International Journal of Celiac Disease 2015; 3:151-155.

7. Udey MC, Stanley JR. Pemphigus--diseases of antidesmosomal autoimmunity. JAM 1999; 282:572-576.

8. Blouin P, Auvrignon A, Pagnier A, Thuret I, Antoni G, Bader-Meunier B, Le Deist F, Chastagner P, Aladjidi N, Pellier I, et al. (Evans'

\section{Acknowledgment}

Authors are grateful to Dr. Jitender Kumar, from the Centre for Computational Biology and Bioinformatics, Amity Institute of Biotechnology for his help in Statistical analysis.

\section{Disclosure of interest}

The authors report no conflict of interest.

\section{Funding}

The authors did not receive funding for this work.

syndrome: a retrospective study from the ship (French Society of Pediatric Hematology and Immunology) (36 cases)). Arch Pediatr 2005; 12:1600-1607.

9. Gonzalez DA, De Leon AC, Rodriguez Perez MC, Coello SD, Gonzalez Hernandez A, Fuentes RC, Jaime AA, Diaz BB. Inverse association between obesity and antinuclear antibodies in women. J Rheumatol 2008; 35:2449-2451.

10. Mathew P, Chen G, Wang W. Evans syndrome: results of a national survey. J Pediatr Hematol Oncol 1997; 19:433-437.

11. Lerner A, Jeremias P, Matthias T. The world incidence and prevalence of autoimmune diseases is increasing. Int J Celiac Dis 2015; 3(4):151-155.

12. https://manualzz.com/doc/29404579/epidemiology-of-musculoskeletal-conditions-in-india

13. Panagariya A, Kumar H, Mathew V, Sharma B. Neuromyotonia: clinical profile of twenty cases from northwest India. Neurol India 2006; 54:382-386

14. Petri M, Orbai AM, Alarcon GS, Gordon C, Merrill JT, Fortin PR, Bruce IN, Isenberg D, Wallace DJ, Nived O, et al. Derivation and 
validation of the Systemic Lupus International Collaborating Clinics classification criteria for systemic lupus erythematosus. Arthritis Rheum 2012; 64:2677-2686.

15. Meroni PL, Schur PH. ANA screening: an old test with new recommendations. Ann Rheum Dis 2010; 69:1420-1422.

16. Agmon-Levin N, Damoiseaux J, Kallenberg C, Sack U, Witte T, Herold M, Bossuyt X, Musset L, Cervera R, Plaza-Lopez A, et al. International recommendations for the assessment of autoantibodies to cellular antigens referred to as anti-nuclear antibodies. Ann Rheum Dis. 2014; 73:17-23.

17. Conrad K, Roggenbuck D, Reinhold D, Sack U. Autoantibody diagnostics in clinical practice. Autoimmun Rev 2012; 11:207-211.

18. Nandiwada SL, Peterson LK, Mayes MD, Jaskowski TD, Malmberg E, Assassi S, Satoh M, Tebo AE. Ethnic Differences in Autoantibody Diversity and Hierarchy: More Clues from a US Cohort of Patients with Systemic Sclerosis. The Journal of rheumatology 2016 Aug 1:160106.

19. Mariz HA, Sato EI, Barbosa SH, Rodrigues SH, Dellavance A, Andrade LE. Pattern on the antinuclear antibody-HEp-2 test is a critical parameter for discriminating antinuclear antibody-positive healthy individuals and patients with autoimmune rheumatic diseases. Arthritis Rheum 2011; 63:191-200.

20. Hayashi N, Koshiba M, Nishimura K, Sugiyama D, Nakamura T, Morinobu S, Kawano S, Kumagai S. Prevalence of disease-specific antinuclear antibodies in general population: estimates from annual physical examinations of residents of a small town over a 5-year period. Mod Rheumatol 2008; 18:153-160.

21. de Vlam K, De Keyser F, Verbruggen G, Vandenbossche M, Vanneuville B, D'Haese D, Veys EM. Detection and identification of antinuclear autoantibodies in the serum of normal blood donors. Clin Exp Rheumatol 1993; 11:393-397.

22. Tan EM, Feltkamp TE, Smolen JS, Butcher B, Dawkins R, Fritzler MJ, Gordon T, Hardin JA, Kalden JR, Lahita RG, et al. Range of antinuclear antibodies in "healthy" individuals. Arthritis Rheum 1997; 40:1601-1611.

23. Sharmin S, Ahmed S, Abu Saleh A, Rahman F, Choudhury MR, Hassan MM. Association of Immunofluorescence pattern of Antinuclear Antibody with Specific Autoantibodies in the Bangladeshi Population. Bangladesh Med Res Counc Bull 2014; 40:74-78.

24. Peene I, Meheus L, Veys EM, De Keyser F. Detection and identification of antinuclear antibodies (ANA) in a large and consecutive cohort of serum samples referred for ANA testing. Ann Rheum Dis 2001; 60:1131-1136.

25. Conrad K, Andrade LE, Chan EK, Mahler M, Meroni PL, Pruijn GJ, Steiner G, Shoenfeld Y. From autoantibody research to standardized diagnostic assays in the management of human diseases report of the 12th Dresden Symposium on Autoantibodies. Lupus 2016; 25:787-796.

26. Wang KY, Yang YH, Chuang YH, Chan PJ, Yu HH, Lee JH, Wang LC, Chiang BL. The initial manifestations and final diagnosis of patients with high and low titers of antinuclear antibodies after 6 months of follow-up. J Microbiol Immunol Infect 2011; 44:222228.

27. Vermeersch P, Bossuyt X. Prevalence and clinical significance of rare antinuclear antibody patterns. Autoimmun Rev 2013; 12:9981003.

28. Imai H, Ochs RL, Kiyosawa K, Furuta S, Nakamura RM, Tan EM. Nucleolar antigens and autoantibodies in hepatocellular carcinoma and other malignancies. AmJ Pathol 1992; 140:859870.

29. Bradwell AR, Hughes RG, Karim AR. Immunofluorescent antinuclear antibody tests. In Detrick B, Hamilton RG, Folds JD, editors. Manual of Molecular and Clinical Laboratory Immunology. 7th ed. Washington D.C. ASM Press; 2006:101-111.

30. Basile U, Gulli F, Torti E, De Matthaeis N, Colacicco L, Cattani P, Rapaccini GL. Anti-nuclear antibody detection in cryoprecipitates: Distinctive patterns in hepatitis C virus-infected patients. Digestive and Liver Disease 2015; 47(1):50-56.

31. Song JS, Do JH, Lee SW. The prevalence and the clinical relevance of anti-Ro52 in Korean patients with primary Sjogren's syndrome. Rheumatol Int 2012; 32:491-495.

32. Satoh M, Chan EK, Ho LA, Rose KM, Parks CG, Cohn RD, Jusko TA, Walker NJ, Germolec DR, Whitt IZ, et al. Prevalence and sociodemographic correlates of antinuclear antibodies in the United States. Arthritis Rheum 2012; 64:2319-2327.

33. Blomberg S, Ronnblom L, Wallgren AC, Nilsson B, Karlsson-Parra A. Anti-SSA/Ro antibody determination by enzyme-linked immunosorbent assay as a supplement to standard immunofluorescence in antinuclear antibody screening. Scandinavian journal of immunology 2000; 51(6):612-617.

34. Tozzoli R, Antico A, Porcelli B, Bassetti D. Automation in indirect immunofluorescence testing: a new step in the evolution of the autoimmunology laboratory. Auto Immun Highlights 2012; 3:59-65.

35. Bizzaro N, Antico A, Platzgummer S, Tonutti E, Bassetti D, Pesente F, Tozzoli R, Tampoia M, Villalta D. Automated antinuclear immunofluorescence antibody screening: a comparative study of six computer-aided diagnostic systems. Autoimmun Rev 2014; 13:292-298.

36. Schur PH, Schmerling RH. Laboratory tests in rheumatic disorders. In: Hochberg MC, Silman A, Smolen J, Weinblatt ME, Weisman M, editors. Rheumatology. 3rd ed. Vol. 1. Edinburgh: Mosby; 2003:343-374.

37. Peng SL, Craft J. Antinuclear antibodies. In: Ruddy S, Harris ED, Sledge CB, editors. Kelly's Textbook of Rheumatology. 6th ed. Vol. 1. Philadelphia: W.B. Saunders Company; 2001:161-173.

38. Sebastian W, Roy A, Kini U, Mullick S. Correlation of antinuclear antibody immunofluorescence patterns with immune profile using line immunoassay in the Indian scenario. Indian Journal of Pathology and Microbiology 2010; 53(3):427. 